\title{
Sectorised versus subspecialist care: what does the patient deserve?
}

\author{
Lucinda Scott
}

Ir J Psych Med 2002; 19(2): 39-41

The backbone of community psychiatry developed with deinstitutionalisation which began first in the US and subsequently in Europe after WWI. This paradigm shift in the care of the mentally ill was fuelled by several overlapping factors including the dissatisfaction with, and economic non-viability of, large hospitals (asylums), ${ }^{1}$ the synthesis of effective major tranquillisers, the rise of social psychiatry ${ }^{2}$ and the improving social conditions due to lower unemployment and the enlargement of the welfare service. The closure of asylums has over subsequent decades led to the examination of the most appropriate conceptual framework for the delivery of comprehensive community mental health services.

In Ireland, the Department of Health report Planning for the Future (1984) signalled the intention to follow a similar strategy of deinstitutionalisation and the development of community services in Ireland. ${ }^{3}$ Sectorisation is the basic framework within which community services have been planned and developed. This article aims to highlight some important aspects of a sectorised model of service delivery and also emphasises the requirement for sup-specialist psychiatric service development in an optimum model of psychiatric care provision.

Sectorisation refers to the responsibility of a team for a specified geographical area which is generally based on a postal district or similar boundary. The principles underpinning a sectorised model of service delivery entail a social model of treatment and a commitment to patientbased services, with an emphasis on prevention and ongoing evaluation, which is, in essence, community psychiatry. The principle sector service is the community mental health team (CMHT) which may be found in a variety of settings and be composed of a variety of professionals but usually including a consultant psychiatrist, community psychiatric nurse (CPN), social workers, occupational therapist and psychologist. In general, it is an ill-defined concept. In a sectorised model core adult psychiatric services are delivered through a network of acute and continuing care beds, day hospitals, day centres and outpatient clinics. Hostels, rehabilitation and training facilities are also part of the community care approach currently being advanced. ${ }^{4}$ In theory, a catchment area/sectorised service model facilitates the development of community based services and allows a more integrated and seamless care for the service user. In a preventive capacity, a designated care team with which the patient and his or her carers have an established relationship may serve to reduce the likelihood of secondary and tertiary handicaps either by prevention of

Lucinda V Scott, MB, PhD, MRCPsych, Department of Psychiatry, Cork University Hospital, Wilton, Cork, Ireland. SUBMITTED: SEPTEMBER 4, 2001. ACCEPTED: FEBRUARY 8, 2002. relapse or the prevention of injurious consequences of relapse such as prolonged hospitalisation. ${ }^{\text {S }}$ Patient and relative satisfaction and burden to relatives are also important factors. Sectorisation affords the concentration of services important to the patient (psychiatric and social work input, housing and benefits advice) and helps avoid the 'pass the parcel' attitude that long term ill and their relatives find so frustrating.

\section{UK experience}

The sectorised service model has been well-developed in the UK since the mid 1980s. Various models of delivering community treatment have been explored including that of assertive community treatment ${ }^{6}$ and intensive case management, ${ }^{7}$ yet the model based on the generic multidisciplinary CMHT remains the pre-eminent one. ${ }^{8}$ Attempts have been made in mental health services research to examine the efficacy of these models in terms of patient satisfaction, quality of life measures, cost-effectiveness, hospital admission rates and psychopathology scores. Although a comprehensive review of various models of community care is beyond the scope of this article, a number of the recent studies are worthy of mention.

The UK 700 trial of intensive versus standard case management of severe psychotic illness failed to find any difference in terms of admission rates, clinical outcome or cost-efficacy, and concluded that UK standard care contained many of the characteristics of assertive outreach services. ${ }^{9}$ The PriSM Psychosis studies also concluded that there was little difference in community mental health team models but that community-orientated services were more effective than hospital-orientated services in terms of health and social gains. ${ }^{10}$

Simmonds et $a l^{11}$ conducted a systematic review of CMHT management of severe mental illness, defined as "a psychiatric illness of sufficient severity to require intensive input and regular review". CMHT management was defined as generic care (ie. care not supplied by ACT, intensive case management or any other specific model) from a community based multi-disciplinary team that provides a full range of interventions to adults (aged 1865 years) with severe mental illness within a defined catchment area. Standard care represented the usual care in the area concerned usually hospital-based out-patient care.

It was concluded that $\mathrm{CMHT}$ management was superior to standard care in promoting a greater acceptance of treatment. CMHT care may reduce length of hospital admissions and avoid deaths by suicide, in addition to increasing service satisfaction among service users. This meta-analysis, presented in greater detail in the Cochrane database of systematic reviews ${ }^{12}$ was based on a sophisticated search strategy in which the authors identified 1,200 citations. However, only five studies were methodologi- 
cally adequate for the comparison of 'CMHT approach' with 'standard care' and only two of these relate to the functioning of a CMHT with responsibility of the total service to a defined catchment area. ${ }^{13,14}$ Given that the CMHT is the central component of the developing psychiatric services policy in Ireland the dearth of strongly supportive evidence for this approach is lamentable. Holloway ${ }^{15}$ asserts that a discussion of the relevance of the CMHT in the UK mental health services model is now supplanted by the issue of add-on assertive outreach, intensive case management and crisis services. The service policy debate appears to have moved on. Indeed, he argues that the generic comprehensive CMHT may disappear in the UK in favour of the North Birmingham model of a group of specialist teams. ${ }^{16}$

\section{One model fits all}

With the development of sectorised services in Ireland the problems of a 'one model fits all' approach to psychiatric service development becomes apparent. This is particularly pertinent for deprived and inner-city sectors which are well-recognised to have a greater frequency of psychiatric morbidity. Glover $e t a l^{17}$ compared the prevalence of mental health problems at primary care, general secondary care and forensic care levels among English health authorities. The most morbid, according to needs indices, have about twice the prevalence of primary care mental illness as the least morbid. For secondary care the ratio is between $2.5: 1$ and $4: 1$, whilst for services for mentally disordered offenders it is in excess of 20:1. Socioeconomic deprivation is a powerful predictor not only of prevalence but also the persistence of mental illness. ${ }^{18}$

The ODIN study of the prevalence of depressive disorders across Europe found urban Dublin to have one of the highest rates of depressive illness. ${ }^{19}$ Some effort is made within the NHS to take account of these factors and to ensure that resources are allocated equitably between health authorities, although the final allocation is not divided according to different clinical areas. ${ }^{20}$ The amount that is actually spent on services is at the discretion of the local health authority. Bindman $e t a l^{21}$ have examined this as a potential cause for inequity. They found that the ratio of expenditure to allocation among different authorities varies widely and that relative underspending on mental health occurs more frequently in deprived areas.

In Ireland, deprivation indices and their association with greater psychiatric morbidity, and the issue of private health insurance are not factored into the sectorised model. In the allocation of resources little attention is paid to poorer sectors within urban areas where all mental health difficulties will present to the public system, unlike other sectors where a considerable proportion of the patients have private mental health insurance which lightens the burden for the public system within these locations. The Future of Psychiatry in Ireland document prepared by the Irish Division of the Royal College of Psychiatrists in 1998 acknowledges this, stating that the population size of sector responsibility should be reduced where severe socioeconomic deprivation exists (centre-city districts, areas of high 'Jarman index'). ${ }^{22}$

\section{Sub-specialisation}

This planning document also aimed to assess how a service based on sectorisation would fit in with the increasing need for specialisation. In the past decade psychiatry, parallelling developments in other medical specialities, has evolved into a number of subspecialty areas. These changes have been impelled both from within psychiatry, where the rapid increase in knowledge and skills make mastery of the entire field by any one practitioner less possible, and from without, related to new expectations for psychiatric services from referral sources and patients. ${ }^{23}$

In Ireland, higher training is available in general and community psychiatry, old age psychiatry, mental handicap/learning disabilities psychiatry and child and adolescent psychiatry subspecialties. ${ }^{22}$ In the Eastern Regional Health Authority's Service Plan 2001 the areas currently identified as requiring specialist service development include mental illness among the homeless, areas of addiction including alcoholism, and the forensic service. ${ }^{4}$ The ERHA does, however, aspire to identifying and providing services that would provide "best practice responses to a known condition" ${ }^{4}$ That a patient with severe treatment resistant depression or an eating disorder has access, if necessary, to an individual with specific expertise in this area is implicit in this statement. This service plan is consistent with the aspirations of The Future of Psychiatry in Ireland document which emphasises the need to encourage general and community consultants to develop special interests, eg. affective disorders, cognitive-behavioural therapy. ${ }^{22}$ It stated explicitly that it should be possible for a service to restructure posts over time to allow for useful special responsibility developments. The key to enabling part-time speciality work to co-exist with sector responsibility lies in protected special sessions alongside reduced sector responsibility in general psychiatry.

Opponents of the increasing academic subspecialisation of psychiatry emphasise the need for the preservation of core skills in psychiatry and the recognition of the continuing public need for general psychiatrists. ${ }^{26}$ These points are entirely reasonable. Yet, that the patient receives optimal treatment remains of paramount importance. In Dublin, the two large private psychiatric hospitals attempt to provide a subspecialist service, eg. a general adult psychiatrist with a special interest in eating disorders, anxiety disorders and affective disorders. This provision is clearly made easier by the absence of restrictions imposed by a sectorised service. It is not apparent that within the public service, in which there may be a number of general adult psychiatrists serving one health board area, that any efforts are made currently to provide a range of special interests within the general adult consultant body. A failure to consider this as an aspect of service improvement does a disservice to the patient population but also to the consultant body, as a system which allows a general psychiatrist to pursue their special interest may improve professional satisfaction and help prevent 'burnout'.

\section{Implications for clinical practice}

Sectorisation has significant implications for clinical practice. A possible consequence of a sectorised service is that the different psychiatrists and psychiatric teams may come to function in an isolationist manner both within the psychiatric services and the medical profession, and that their spread into the community can lead to the development of closed subcultures often characterised by resistance to change, a lack of academic motivation ${ }^{23}$ and a tendency for professionals to become deskilled. Concerns have also been raised that staff 'burnout' may make 
too had a I fe, laughter filled with $^{\circ}$, lars.

we made Wonderful

PLANS

for our lateryears.

'Mos 1 and 'r' frightened,

Because of my illness,

I'm no longer the

same,

вut reach out and $_{\text {iouch }}$

I'm more than a name.

мове тHAN A Name by Jerry Ham (Alzheimer's carer)

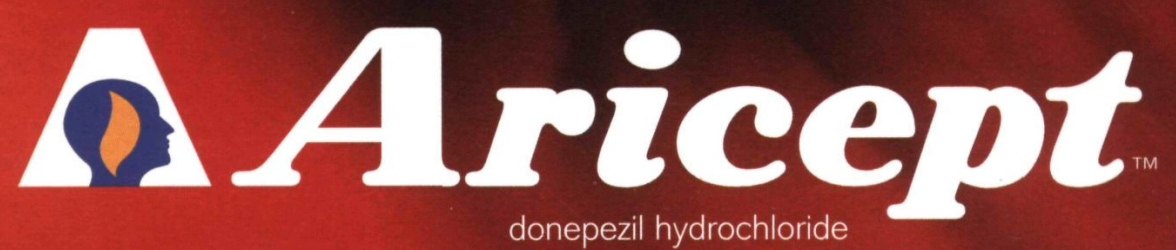

Making a difference in Alzheimer's

BRIEF PRESCRIBING INFORMATION
ARICEPT (donepezil hydrochloride)Please refer to the
SmPC before prescribing ARICEPT $5 \mathrm{mg}$ or ARICEPT
10mg. Indication: Symptomatic treatment of mild to CNS administration: Adults/elderlerly's 5 dementia. Dose and CNS Sadministration: Adults/elderly; $5 \mathrm{mg}$ daily which may be
oiscovenv increased to $10 \mathrm{mg}$ once daily atter at least one month. No dose adjustment necessary for patients with renal or mild-moderate Indications: Pregnancy. Hypersensitivity to donepezil, piperidine derivatives or any excipients used in ARICEPT. Lactation: Excretion into breast milk unknown. Women on donepezil should not breast
feed. Warnings and Precautions: Initiation and supervision by a Dhysician with experience of Alzheimer's dementia. A caregiver should
available to monitor compliance. Regular monitoring to ensure Jntinued therapeutic benefit, consider discontinuation when evidence of a therapeutic effect ceases. Exaggeration of succinylcholine-type
muscle relaxation. Avoid concurrent use of anticholinesterases cholinergic agonists, cholinergic antagonists. Possibility of vagotonic
effect on the heart which may be particularly important with "sick sinus syndrome", and supraventricular conduction conditions. There Syncope, bradycardia, and rare cases of sinoatrial block and
have been reports of syncope and seizures - in such patients the atrioventricular block, and seizure have been reported. Rare reports of have ben reports of syncope and seizures - in such patients the atrioventricular block, and seizure have been reported. Rare reports o
possibility of heart block or long sinusal pauses should be considered. liver dysfunction including hepatitis. Pyychiatric disturbances, Careful monitoring of patients at risk of ulcer disease including those including hallucinations, agitation and aggressive behaviour have also receiving NSAIDS. Cholinomimetics may cause bladder outflow been reported; these resolved on dose reduction or discontinuation.
obstruction. Seizures occur in Alzheimer's disease and There have been some reports of anorexia, gastric and duodenal

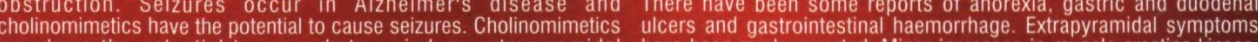
may have the potential to exacerbate or induce extrapyramidai have been rarely reported. Minor increases in muscle creatine kinase. symptoms. Care in patients suffering asthma and obstructive Presentation: Blister packed in strips of 14. ARICEPT 5mg: white, film pulmonary disease. As with all Alzheimer's patients, routine evaluation coated tablets marked 5 and ARICEPT, packs of 28. ARICEPT 10mg; of ability to drive/operate machinery. Drug Interactions: Experience of yellow, film coated tablets marked 10 and ARICEPT, packs of 28. Ise with concomitant medications is limited, consider possibility of as Marketing authorisation numbers: ARICEPT 5mg; PA 822/2/1. yet unknown interactions. Interaction possible with inhibitors or ARICEPT 10mg; PA 822/2/2. Marketing authorisation holder: Prizer Potential to interfere with anticholinergic agents. Possible synergistic Republic of Ireland. Further information from/Marketed by: activity with succinylcholine-type muscle relaxants, beta-blockers or Pfizer (Ireland) Ltd... Parkway House, Ballymount Road Lower. Dublin cholinergic agents. Side effects: Most commonly diarrhoea, muscle 12, Republic of Ireland. Date of preparation: September 2000. 
community mental health care difficult to sustain. ${ }^{24}$ This is particularly relevant if resources required to implement a service that is comprehensive and satisfactory to the patient and the clinical team are inadequate. The underdevelopment of community resources is reflected in the considerable variations in the provision of community psychiatric services (day hospitals, day centres, community residences) throughout the different health board areas. For example, the number of day centre places ranged from 178.5 per 100,000 population in the North Western Health Board to 34 per 100,000 in the Northern Area Health Board. ${ }^{25}$

In Ireland, as a consequence of sectorisation, public psychiatry is the only speciality where a patient is not allowed to chose their clinician. This may be interpreted as an infringement on the rights and autonomy of mental health patient population and impact negatively on the doctor/patient relationship which, in cases of major mental illnesses, may be a lifelong one. While general practitioner's will generally find it useful to have a specific consultant psychiatrist to whom they refer and with whom they can establish a relationship, some may find the sectorised model restrictive and unsatisfactory, as may service users.

The relatively late conversion to sectorisation in Ireland, compared to the UK, is helpful in allowing the advantages and disadvantages of a sectorised model to be explored. It is not appropriate that a sectorised model of care be pursued without considering the requirement of specialist service development in parallel. Flexibility at consultant and health board level are required to facilitate this mixed approach. The development of tertiary referral centres, which would be academically driven and funded by the different health boards purchasing services for specific problematic cases, should also be encouraged.

\section{References}

1. Martin JP. Hospitals in Trouble, Blackwell. 1984

2 . Bachrach $\mathrm{L}$. The legacy of model programmes. Hospital and Community Psychiatry 1989; 40.
3. Building for the Future, Department of Health.1984.

4. Eastern Regional Health Authority, Service Plan. 2001. www.ehra.ie/Reports/ServicePlan 2001

5 . Thornicroft $G$. The case for catchment areas for mental health services. Psychiatr Bull 1995; 19: 343-6.

6. Marshall M, Lockwood A. Assertive community treatment for people with severe mental disorders. Cochrane Library, Issue 4. Oxford: Update Software. 7. Hassiotis A, Ukoumunne O, Byford S, Tyrer $P$ et al. Intellectual functioning and outcome of patients with severe psychotic illness randomised to intensive case management. Br J Psychiatry 2001; 178: 166-71.

8. Thornicroft G, Becker T, Holloway $F$ et al. Community mental health teams: evidence or belief? Br J Psychiatry 1999; 175: 508-13.

9.Byford S, Fiander M, Torgerson D, Barber J et al. Cost-effectiveness of intensive $\mathrm{v}$ standard case management for severe psychotic illness. $\mathrm{Br} \mathrm{J}$ Psychiatry 2000; 176: 537-43.

10. Thornicroft G, Wykes T, Holloway F, Johnson S, Szmukler G. From efficacy to effectiveness in community mental health services. PriSM Psychosis Study. 10. Br J Psychiatry $1998 ; 173: 423-7$

11. Simmonds S, Coid J, Joseph P, Marriott S, Tyrer P. Community mental health team management in severe mental illness: a systematic review. $\mathrm{Br} \mathrm{J}$ Psychiatry 2001; 178: 497-502.

12. Tyrer P, Coid J, SOimmonds S et al. Community mental health team management for those with severe mental illness and disordered personality. Cochrane Library, issue 3. Oxford: Update Software.

13. Tyrer P, Evans K, Gandhi N et al. Randomised controlled trial of two 13. Tyrer P, Evans K, Gandhi $N$ et al. Randomised controlled trial of two
models of care for discharged psychiatric patients. Br Med J 1998; 316: 106-9. 14. Burns T, Beadsmore A, Bhat A et al. A controlled trial of home-based acute psychiatric services. I. Clinical and social outcome. Br J Psychiatry 1993; 163 : 49-54.

15. Peck E. Introduction to special section on community mental health teams. J Ment Health 1999; 8: 215-6.

16. Holloway F. Invited commentary on: Community mental health team management in severe mental illness. Br J Psychiatry 2001; 178: 503-505. 17. Glover GR, Leese M, McCrone P. More severe mental illness is more concentrated in deprived areas. Br J Psychiatry 1999; 175: 544-8.

18. Ostler K, Thompson C, Kinmonth A-L, Peveler R, Stevens L, Stevens A. Influence of socio-economic deprivation on the prevalence and outcome of depression in primary care.Br J Psychiatry 2001; 178: 12-7.

19. Ayuso-Mateos J, Vasquez-Barquero J, Dowrick C et al. Depressive disorders in Europe: prevalence figures from the ODIN study. Br J Psychiatry 2001; 179 308-16.

20. Smith $P$, Sheldon T, Carr-Hill R et al. Allocating resources to health authorities: results and policy implications of small area analysis of use of inpatient services. Br Med J 1994; 309: 1050-4.

21. Bindman J, Glover G, Goldberg D, Chisholm D. Expenditure on mental health care by English health authorities: a potential cause of inequity. $\mathrm{Br} \mathrm{J}$ Psychiatry 2000; 177: 267-274.

22. Webb M. The Future of Psychiatry in Ireland. Irish Division of the Royal College of Psychiatrists, 1998.

23. Borgeat $F$. Some consequences of catchment area psychiatry: a stand against sectorisation. Can J Psychiatry 1994; 39: 85-90.

24. Prosser D, Johnson S, Kuipers E et al. Mental health, 'burnout' and job satisfaction among hospital and community-based mental health staff. $\mathrm{Br}$ Psychiatry 1996; 169: 334-7.

25. Daly A, Walsh D. Activities of Irish Psychiatric Services 2000. Mental Health Research Division, Health Research Board.

26. Goldbloom DS, Buckingham RA, Voore P. Rediscovering general psychiatry: creation of an academic division. Can J Psychiatry 1997; 42: 58-62.

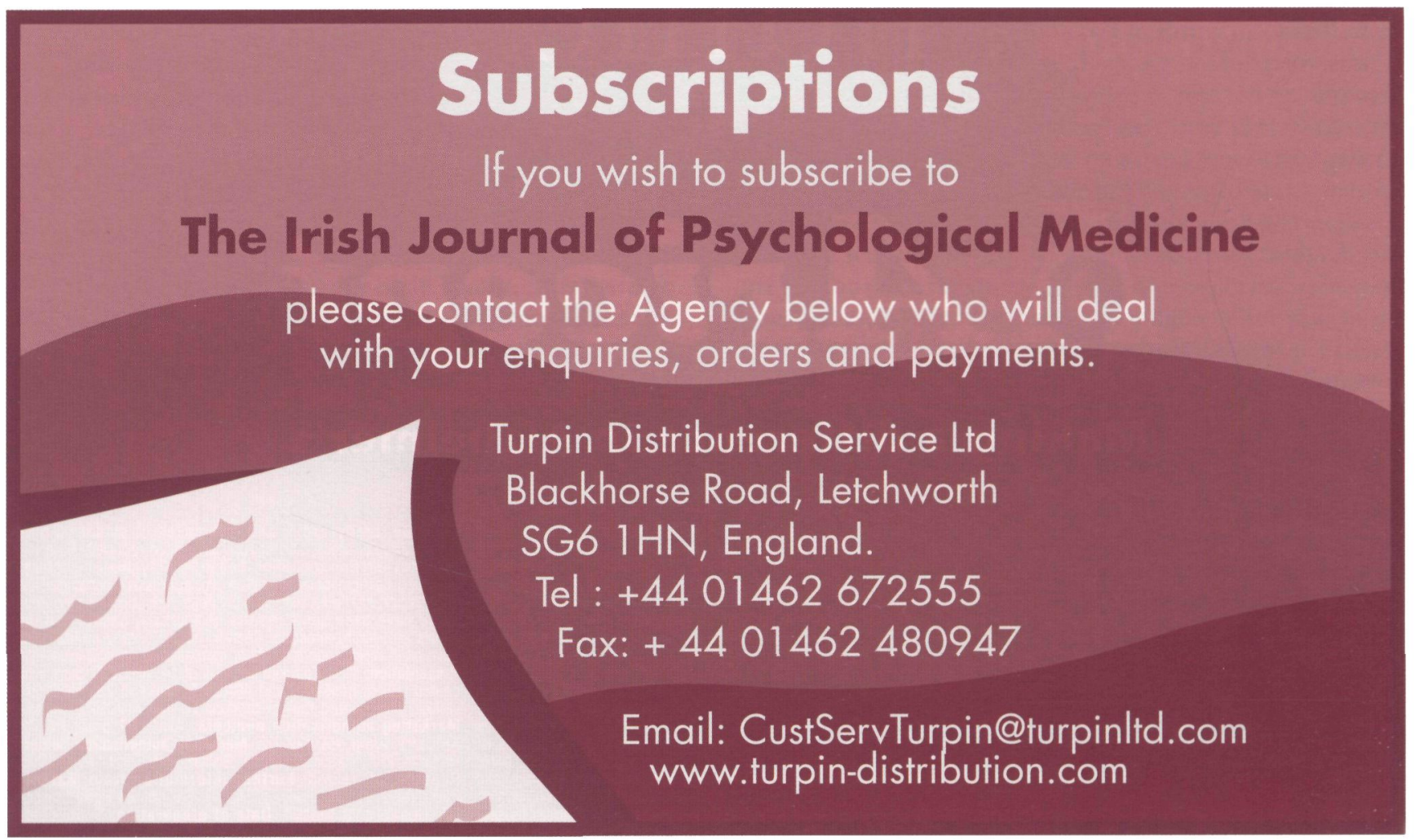

